\title{
Del espacio a la causa: el item polisémico de la preposición por
}

\section{From space to causation: the polysemic item of the Spanish preposition por}

\author{
María Soledad Funes \\ Universidad de Buenos Aires, Buenos Aires, Argentina / CONICET \\ solefunes@gmail.com
}

GACCESO ABIERTO / OPEN ACCESS

Cita: Funes, María Soledad (2020). Del espacio a la causa: el ítem polisémico de la preposición por. Textos en Proceso, 6(1), pp. 27-54. https://doi.org/10.17710/tep.2020.6. 1.2 funes

Editores: Esperanza Alcaide Lara, Universidad de Sevilla, Ana Pano Alamán, Università di Bologna

Recibido: 30-03.-2020

Aceptado: 22-05-2020

Conflicto de intereses: La autora ha declarado que no posee conflicto de intereses.

Copyright: (c) María Soledad Funes. Esta obra está bajo licencia Creative Commons Reconocimiento 4.0.

\section{Resumen}

No hay acuerdo en las gramáticas respecto de la caracterización semántica de la preposición por. Por un lado, hay una falta de sistematización de los usos (como, por ejemplo, en el Esbozo (Real Academia Española, 1973), en De Bruyne (1999), y en la Nueva Gramática de la Lengua Española (Real Academia Española, 2009). Es decir, se presentan en listados sin relación entre sí. También sucede el problema opuesto, que es presentar un solo valor, como Fernández Lagunilla y Anula Rebollo (1995), quienes reducen el significado de por a [+causa] (1995: §7.6.3.1). Ante esta falta de acuerdo, el presente trabajo propone una descripción semántica de la preposición por a partir de los presupuestos teóricos del Enfoque Cognitivo Prototípico, sobre todo la teoría de categorización radial de Lakoff (1987). De este modo, se plantea que los distintos valores semánticos de la preposición por están organizados sistemáticamente y constituyen pragmático-semánticamente un ítem polisémico. El atributo pragmático-semántico más prototípico es [+Locativo]. Las construcciones con por que se alejan del significado prototípico dependen de este por la pérdida/adición de otros atributos o por disminución/aumento de la presencia de ciertos atributos. Para demostrar estas hipótesis, se analizaron cualitativa y cuantitativamente 12 entrevistas del corpus PRESEEA-Buenos Aires (2010-2011).

Palabras clave: Enfoque Cognitivo Prototípico; polisemia; prototipo; preposición por.

\begin{abstract}
There is no consensual description of the semantic characterization of preposition por in grammar studies. There is a lack of systematization of its uses, which are usually listed as unrelated items -as seen on Esbozo (Real Academia Española, 1973), in De Bruyne (1999) and in Nueva Gramática de la Lengua Española (Real Academia Española, 2009)-. But there is also the opposite problem: the reduction
\end{abstract}


to a single value, as seen in Fernández Lagunilla \& Anula Rebollo (1995), where the meaning of por is reduced to [+cause] (1995: §7.6.3.1). Given this lack of consensus, this article proposes a semantical description of the preposition por, following the theoretical guidelines of the Prototypical Cognitive Approach, and mainly Lakoff's theory of radial categorization (1987). Thus, different semantic values of the preposition por are organized systematically, so that they pragmatically-semantically constitute a polysemic item. The most prototypical pragmatic-semantic attribute is [+Locative]. Por constructions that diverge from said prototypical meaning are still dependent on it, through addition/subtraction of attributes, diminution/augmentation of certain others. To demonstrate this hypothesis, a qualitative and quantitative analysis of 12 interviews from the corpus PRESEEA-Buenos Aires (2010-2011) was made.

Keywords: Prototypical Cognitive Approach; polysemy; prototype; preposition por.

\section{Introducción}

El presente trabajo forma parte de una investigación mayor, que tiene su origen en los resultados obtenidos en dos estudios previos. En el primero de ellos (Funes, 2015), se analiza el uso de la preposición de en contexto nominal ('nominal $+d e+$ nominal', como en la casa de Sonia) y en el segundo trabajo (Funes, 2016), se realiza un estudio comparativo del uso de las preposiciones de y por en construcciones pasivas, en el español de Buenos Aires, con el objetivo de continuar el trabajo iniciado sobre el uso de la preposición de, en este caso en variación con por.

En Funes (2016), se analiza la alternancia de las preposiciones de y por en contexto de Complemento Agente (CAg), en dos cuerpos de datos (uno oral y otro escrito). A partir del análisis de los corpora, se obtuvieron las siguientes conclusiones: en corpus escrito, hay mayor frecuencia de construcciones pasivas que en corpus oral. En las construcciones pasivas con complemento agente explícito, hay mayor frecuencia de aparición de CAg introducidos por por, en contraste con los introducidos por $d e$, de los que hallamos muy pocos casos. Además, existe una jerarquía en los atributos de las construcciones pasivas, en cuanto a la elección de cada preposición. Los atributos que tienen más peso son el tipo de predicación y el grado de afectación del paciente, seguido de los atributos del agente. De esta manera, cuando el hablante elige la preposición por para introducir un $\mathrm{CAg}$, lo hace en contexto de predicaciones dinámicas, es decir, con cercanía al Modelo cognitivo idealizado (MCI) de bola de billar, ${ }^{1}$ con pacientes altamente afectados, y agentes con los atributos [+humano] y [+determinado]. Cuando el hablante elige la preposición de para introducir un CAg, lo hace en

\footnotetext{
${ }^{1}$ Para el Enfoque Cognitivo Prototípico, marco teórico en el que se inscribe el presente trabajo, entre los principios generales de organización de la cognición se encuentran los Modelos Cognitivos Idealizados (MCI), mediante los cuales se organizan los conocimientos. Al respecto, Lakoff (1987) postula que los hablantes organizan el conocimiento mediante estructuras de MCI, que son los sostenes de las categorías entendidas en términos graduales o no graduales. En relación con la Gramática, existen dos modelos cognitivos idealizados (MCI) que están en la base de la conceptualización de los nombres y de los verbos: el MCI de escenario, donde se objetiviza la interacción de un participante con una región; y el MCI de bola de billar o cadena de acción, donde los objetos físicos discretos se mueven e interactúan energéticamente cuando entran en contacto (Langacker, 1991).
} 
contextos de predicaciones estáticas (cercanas al MCI de escenario), con paciente poco o nulamente afectados, y con agentes [-humanos] y [-determinados]. El hecho de que la preposición de aparezca en predicaciones estáticas se relaciona con su significado básico de posesión (relación estática), lo que justifica también que el tipo de predicación sea el atributo de mayor peso.

Considerando los resultados anteriores, resta por analizar en profundidad la preposición por, para completar la caracterización de los usos en los que aparece sin variar con $d e, \mathrm{y}$ de ese modo entender por qué la preposición por aparece en contextos agentivos dinámicos.

En función de lo previamente descrito, y como el uso de preposiciones registra una interesante variación dialectal ${ }^{2}$, el objetivo del presente trabajo es describir, con una metodología empírica y tomando como contexto máximo el discurso, el uso de la preposición por en la variedad del español de la ciudad de Buenos Aires. Se sostiene la hipótesis de que los distintos valores semánticos de la preposición por están organizados sistemáticamente y constituyen pragmáticosemánticamente un ítem polisémico. El atributo pragmático-semántico más prototípico es [+Locativo], entendiendo por tal el significado espacial de extensión imprecisa. Es decir, el significado locativo reúne los atributos [+Trayectoria], [+Extensión] e [+Imprecisión], que son los atributos básicos que dan cuenta del prototipo de por. Estos atributos luego reaparecen en los otros significados, a veces por proyección metafórica (como en el significado temporal o causal), otras veces compartiendo sólo el atributo [+Imprecisión]. Esto es, las construcciones con por que se alejan del significado prototípico dependen de este por la pérdida/adición de otros atributos; o por disminución/aumento de la presencia de ciertos atributos.

La investigación se enmarca en el Enfoque Cognitivo Prototípico (ECP) (Lakoff, 1987; Langacker, 1987, 1991 y Geeraerts y Cuyckens, 2007, entre otros). De este enfoque teórico, se retomarán fundamentalmente los postulados que plantean que no existen formas lingüísticas sin significado y que los valores semánticos provienen de la regularidad de su empleo en el discurso. También se retomarán la Teoría de Prototipos de Rosch, y la reformulación de Lakoff acerca del modelo de categorización radial para sostener cómo está constituido el ítem polisémico que conforma la preposición por. Este ítem polisémico presenta una estructura de categoría radial (Lakoff, 1987), cuyo significado central es el de locativo. Para comprobar las hipótesis, se analizó cualitativa y cuantitativamente una selección de 12 entrevistas del corpus oral PRESEEA-Buenos Aires, que presenta usos de los años 2010 y 2011.

A continuación, en primer lugar, se resumirán los presupuestos teóricos fundamentales del Enfoque Cognitivo Prototípico. Luego, se expondrá un breve estado de la cuestión sobre la preposición por y los problemas teóricos pendientes. Seguidamente, se explicará la Metodología; se describirán el corpus elegido, el análisis cuantitativo y el análisis cualitativo con ejemplos seleccionados. Finalmente, se detallará la conformación del ítem polisémico y se presentarán las conclusiones.

\footnotetext{
${ }^{2}$ Considérese que dentro de la Argentina hay una importante variación dialectal en el uso de las preposiciones y, puntualmente, hay registro de variación del uso de por (Vidal de Battini, 1964, pp. 194-196).
} 


\section{Breve descripción del marco teórico: el Enfoque Cognitivo Prototípico}

El Enfoque Cognitivo Prototípico (ECP) presupone que, como el hablante siempre dice lo que (desde algún lugar) quiere decir, en la búsqueda de claridad y de obtención de su objetivo comunicativo no usa formas inútilmente, porque estas son instrumentos para lograr sus objetivos, es decir que toda forma del mensaje tiene un significado (no habría palabras, preposiciones, "vacías"). En cuanto a la categorización de la realidad, según la teoría clásica de categorización las categorías tienen límites precisos, sus miembros son representantes equivalentes, poseen una calidad y cantidad idéntica de propiedades necesarias y suficientes que responden a una distribución binaria y discreta. Esta concepción es propia de los modelos de signo arbitrario, en los cuales la descripción de las unidades se hace en función de un criterio de economía, donde menos es más, y en beneficio de la autoconsistencia del propio modelo, y no en función de las condiciones de uso de dichas unidades.

Desde el ECP, una categoría es una unidad cultural de uso que representa el conocimiento de la forma de uso de esa categoría; el conocimiento tiene una estructura no arbitraria sino motivada por el uso del objeto en situaciones reales (Rosch, 1978). Los miembros de una categoría no son idénticos sino semejantes y sus atributos no están siempre todos presentes en la misma medida en cada miembro de la categoría, por lo que habrá atributos más y menos salientes. Por esto, la categoría presenta miembros más prototípicos que otros, que muestran límites no necesariamente precisos entre sí y que no están necesariamente organizados de modo binario. El prototipo es un esquema abstracto que reúne en sí la mayor cantidad de atributos comunes a todos los miembros de la categoría. Esta concepción de la categorización resulta útil a la hora de describir, por ejemplo, la preposición por, porque ofrece estrategias de análisis que permiten incluir sistemáticamente todos los usos de una forma en una misma categoría, marcando una tendencia hacia la polisemia más que hacia la homonimia.

Para Langacker, la preposición es ante todo una predicación relacional, es decir, un nexo entre un origen y un destino (1987, pp. 214-217). Para la gramática cognitiva, toda preposición, como todo lexema o morfema, tiene siempre un significado. Este varía según el contexto, puesto que cada palabra actualiza (parte de) su significado al entrar en relación con distintos elementos en cada situación de uso. Para el ECP, lo que debe caracterizarse y describirse son las redes semánticas que posibilitan una realización fonológica común, estudiar y sistematizar los distintos significados relacionados y las relaciones significativas en sí, siendo la homonimia el punto final a lo largo de un continuo relacional, es decir, un caso límite de polisemia donde la única relación entre los significados viene dada por la expresión (Langacker, 1987, p.137). En este sentido, la polisemia es una relación sistemática entre las significaciones, y afecta a la organización cognitiva del léxico. La polisemia es un caso especial de categorización basada en prototipos donde los sentidos de una palabra son los miembros de una categoría; la idea es que la teoría de prototipos trata de poner orden al caos significativo (Lakoff, 1987, pp. 316, 334 y 378; Taylor, 1989, pp. 300-303). Estos presupuestos teóricos orientan las hipótesis planteadas en el presente trabajo.

\section{Sobre la preposición por}

Las gramáticas hispánicas en general concuerdan en darle a la preposición por una serie de significados no sistematizados entre sí. Por ejemplo, el Esbozo (Real 
Academia Española, 1973) lista los usos de por y ubica en primer lugar el de agente de pasiva: "Por: sirve en primer lugar para distinguir la persona agente en las oraciones de pasiva: El mundo fue hecho por Dios." (1973: §3.11.5.) Luego, se agregan otros significados, a saber: expresión del fin u objeto de nuestras acciones (Salgo con gabán, por ir más abrigado); ${ }^{3}$ duración o tiempo aproximado (Me ausento de Madrid por un mes); lugar (Pasa por la calle); causa o motivo (Se cerró el aeródromo por la nevada. Lo hago por tu bien); medio (Casarse por poderes. Llamar por teléfono); modo (Lo hace por fuerza, vende por mayor); precio o cuantía (Venderá la casa por dinero. Por docenas); equivalencia (Váyase lo uno por lo otro. Pocos soldados buenos valen por un ejército); 'en busca de' (Va por leña), 'en favor de' (Votemos por Juan), 'en lugar de' (Si no paga, yo pagaré por él); cambio o trueque (Doy mi gabán por el tuyo); 'en concepto u opinión de' (Se le tiene por bueno. Pasa por rico.); equivale al significado de la preposición sin (La casa está por barrer. La carta, por escribir), ' 'en clase o calidad de' (Le tomé por criado. Lo recibió por esposa). Finalmente, se menciona que forma locuciones concesivas (por grande que sea, por mucho que digas) (1973: §3.11.5.).

Alcina Franch y Blecua (1975), en la clasificación de preposiciones llenas y vacías que proponen, incluyen a por en ambos grupos, ya que advierten que por "en algunos aspectos" (no especificados por los autores) es vacía, mientras que en otros, es llena, es decir, significa por sí misma. Luego, listan una serie de ejemplos, que, entendemos, se refieren a los usos plenos de por. Estos usos se dividen en expresiones de lugar, tiempo, causa y finalidad, y modo. Cuando por expresa lugar, indica el lugar a través del cual se realiza la acción (Pasea por la calle). Cuando expresa el tiempo, se refiere al momento de la acción (Por la noche). En la expresión de causa y finalidad, la preposición por puede expresar finalidad en contexto de verbos de movimiento (Voy por agua). Llamativamente, los autores no dan ejemplos de uso de por causal. Finalmente, dicen que por puede expresar modo (Por ventura) (1975: §6.2).

De Bruyne (1999), en la Gramática Descriptiva de la Lengua Española, elabora una lista de usos de la preposición por, retomando en gran parte al Esbozo (1973). Al inicio, el autor señala que "Por es la más plurifuncional de todas las preposiciones españolas” (1999, p. 891), y más adelante reproduce la lista del Esbozo e incluso repite varios ejemplos. Así, en primer lugar, menciona el uso en complemento agente de pasiva de por (Fue desheredado por su padre), al que añade el uso en pasivas reflejas (Se firmó la paz por los embajadores) y frases elípticas (doctor por la Universidad de León, diputado por Valladolid), con el mismo significado agentivo. En cuanto al uso de por en contexto similar al de para (como en El niño se esfuerza por levantar la piedra), De Bruyne ensaya una explicación: "Quizá el uso de por implique a veces en la mente del hablante un leve matiz causal" (1999, p. 862). En cuanto al valor temporal, también diferencia por de para. En los ejemplos Vendré por Navidad versus Vendré para Navidad, por Navidad abarca un

\footnotetext{
${ }^{3}$ En este caso, el Esbozo advierte que es un significado muy cercano al de la preposición para, pero no explica la relación entre ambas preposiciones, o cuál sería exactamente la diferencia entre usar una u otra.

${ }^{4}$ No creemos que en esos ejemplos (La casa está por barrer. La carta, por escribir) el significado de por sea intercambiable por el de la preposición sin. Atendiendo al significado de la oración, en $L a$ carta está sin escribir, todavía no sabemos si esa carta se escribirá o no, mientras que en La carta está por escribir supone que es inminente o en algún sentido, es un hecho futuro que una persona efectivamente escribirá la carta. Además, desde el Enfoque Cognitivo Prototípico, a cada forma le corresponde un significado, por lo que no habría formas (preposiciones, en este caso) intercambiables.
} 
espacio temporal que comienza antes y termina después del 25 de diciembre. Vendré para Navidad significa, en cambio, que de todas formas la persona estará el día indicado (aunque la llegada pueda ocurrir antes) (1999, p. 683). En el resto de los usos, sigue al Esbozo (De Bruyne, 1999, pp. 684-691).

Fernández Lagunilla y Anula Rebollo (1995) incluyen a por en el grupo de preposiciones llenas y le adjudican el significado de [+causa] (La abuela está triste por los disgustos) (1995: §7.6.3.1). Resulta llamativo que el ejemplo elegido por los autores no contemple que al dictaminar como significado [+causa] (sin pensar en la convivencia con otro(s) atributo(s) ni una jerarquización de atributos entre sí (probablemente, entre otras razones, porque el modelo teórico que siguen no lo permitiría), no contemplen la importancia de destacar que la causa más prototípica se espera que tenga voluntad o intencionalidad, algo que los disgustos -en el ejemplo- no manifiesta. Podemos pensar que, aunque no lo digan de manera explícita, otros autores sí han percibido la importancia de este factor al mencionar en primer lugar el contexto de complemento agente. Es interesante, además, notar que la idea de un significado de 'causa' como abarcador de los demás significados (agente, especialmente) aparece también en la caracterización de los actantes en una cláusula transitiva en Langacker (1991, pp. 285-289).

Finalmente, la Nueva Gramática de la Lengua Española (Real Academia Española, 2009) -NGLE- basa su descripción de la preposición por a partir de las semejanzas con para. Señala que ambas preposiciones tienen usos cercanos por razones históricas:

Ambas derivan de una forma iberorrománica por en la que habían confluido formal y semánticamente las preposiciones latinas pro, que denotaba 'posición delantera o anterior', pero también 'sustitución' y 'causalidad o finalidad', y per, que expresaba 'movimiento a través', además de 'instrumento' y 'causalidad'. El resultado fue una preposición de significado tanto causal como final (...) Un proceso lento condujo a la diferenciación paulatina de por y para y a su especialización en los valores de causalidad y finalidad. Sin embargo, dicha especialización no impidió que por mantuviese su valor causal y final originario. En la lengua actual, ambas preposiciones son prácticamente intercambiables en un buen número de contextos, sobre todo con subordinadas de infinitivo negadas (Me río por-para no llorar). (...) Suele preferirse por cuando las nociones de causa y finalidad se identifican o se confunden en una misma entidad, como en todo por la patria (2009: §29.8n).

Aquí se advierte que para la $N G L E$ hay contextos en los que por y para son intercambiables, cuestión en principio inadmisible para el enfoque en el que se inscribe el presente trabajo, dado que a cada forma le corresponde un significado. Más adelante, la $N G L E$ ofrece una lista de usos de por que se asemeja bastante a la del Esbozo. Se trata de los siguientes significados: lugar que expresa el trayecto o curso de un movimiento (Paseaban por el centro de la calle), así como la ubicación aproximada de algo (No veo nada por aqui). Este último sentido de localización inexacta se extiende a los complementos temporales, como en El suceso tuvo lugar allá por los años treinta; temporal (Estaré aqui por tres meses); uso expletivo (Por dos veces todavía giró la cabeza); complemento agente (El manifiesto fue firmado por numerosas personas); causa (Está cerrado por vacaciones. Lo regañaron por perezoso y por hablar con sus compañeras); significado de 'en favor de' (trabajar por la paz); los medios o recursos empleados en alguna acción (habian tomado la sede por la fuerza), la vía por la que se envía o recibe algo (por teléfono), la cantidad por la que se vende o se compra alguna cosa (Lo había adquirido por muy poco dinero), la persona o cosa que sustituye a otra (Iré yo por él), y también lo que se 
busca o se persigue, sobre todo con verbos de movimiento (ir por leña). Señala indicio, a menudo en posición temática (Por la cara que puso, yo diría que no sabía nada), así como la persona que no objeta alguna actuación (Por mí, que se maten) (2009: §29.8o-§29.8q).

En cuanto a los trabajos monográficos sobre preposiciones, se encuentra el de M. L. López (1972), quien parte de la teoría de Pottier (1962) sobre la sistematización de las preposiciones en francés. Según esta teoría, existen dos universos: el dimensional y el nocional. A su vez, el universo dimensional está considerado a través del Espacio y del Tiempo. Por tanto, cada preposición tendrá que ser estudiada a través de estos tres aspectos: Espacio, Tiempo y Noción. Pottier establece un esquema para cada preposición, en el que describe la representación única de cada una, que consta de aplicación espacial, aplicación temporal y aplicación nocional (todas se encuentran al mismo nivel). De cada aplicación surgen ejemplos extraídos del discurso (Pottier, 1962, p 127). A su entender, cada preposición no tiene a nivel de lengua más que una significación, y esta significación está formada por la reunión de un cierto número de atributos pertinentes que forman una imagen susceptible de ser dibujada grosso modo. Esto se complementa añadiendo que es en el discurso donde las preposiciones adquieren matices nacidos del contexto. Cada preposición tendría un valor espacial, otro temporal y otro nocional, tal como en: Llegó a Madrid (espacial) $\rightarrow$ Llegó a las cuatro de la tarde (temporal) $\rightarrow$ Llegó a una conclusión errónea (nocional). En lo que respecta a la preposición por, López retoma la representación esquemática de Pottier:

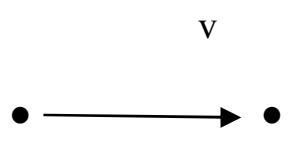

POR

En el esquema, por denota duración, recorrido y unión pasada (López, 1972, p. 138). La autora luego da los ejemplos del discurso correspondientes a por: un valor espacial (por el bosque, por el río, por la carretera), un valor temporal (por dos días, por el verano, por un año), y un valor nocional (por su riqueza, por amor), sin aclarar que se trataría de un valor causal.

Morera Pérez (1988), en su extenso estudio sobre las preposiciones en español, parte de la hipótesis de que cada preposición tiene una forma semántica única, que surge de sus relaciones opositivas con los demás miembros del paradigma preposicional, y que permite explicar todas las variaciones de sentido que se producen en el contexto (Morera Pérez, 1988, p. 43). Cada preposición se describe mediante una combinación específica de rasgos atribuidos según un esquema binario. Morera toma los rasgos del estudio de Guillaume (1953, pp. 243$244)^{5}$.

Considerando estos rasgos, Morera Pérez caracteriza a por con los semas [+sentido] y [+concomitancia] (1988), p. 52). Más adelante, agrega: "Los semas inherentes de la preposición por: [+sentido] y [+concomitancia], que podemos

\footnotetext{
${ }^{5}$ Los rasgos son: [+/-sentido]; [+/- concomitancia]; [+/- aféresis]; [+/- bloqueo]; [+finitivo] / [infinitivo]; [+/-extensión]; [+/- determinación]; [+/-adecuación]; [+/-acompañamiento]; [+absoluto]/ [+relativo]; [+limitada] / [+orientada]; [+vertical] / [+horizontal]; [+anterioridad] / [+posterioridad]; [+superioridad] / [+inferioridad] (Morera Pérez, 1988, p. 86 y ss.).
} 
denominar con el nombre genérico 'tránsito', que implica solidariamente los rasgos de contenido 'extensión', 'ausencia de límites', 'movimiento', 'indiferencia a la dirección', etc., dan cuenta de todas las variantes que se estudian” (1988, p. 287).

Se advierte, solo considerando los ejemplos que citan los autores antes reseñados, que la descripción de Morera responde a matices demasiado abstractos, que no dan cuenta de las relaciones entre los significados descritos de por.

Delbecque (1996), desde una perspectiva afín al Enfoque Cognitivo Prototípico, propone que el significado básico de por es el de 'factor condicionante' (conditioning factor). Esto es, que la preposición por señala la "explicación del surgimiento de la entidad expresada por el sujeto preposicional”. En Y por X, X es la condición preconceptualizada que permite la comprensión de Y. Por ejemplo, en viajes por todo el mundo, la conceptualización del objeto preposicional ${ }^{6}$ (todo el mundo) es precedente a la de viajes. Según la autora, de este significado derivan todos los demás que puede expresar por (causa, temporal, locativo, etc.). Para demostrar su hipótesis, analiza ejemplos de un corpus escrito variado, conformado por diversos ensayos. Sin embargo, no aparecen las fuentes citadas, por lo que no podemos saber ni el origen ni la época de los ejemplos.

Finalmente, y también desde una perspectiva cognitivista, se destaca el trabajo de Kontturi (2010). El autor presenta una red semántica que intenta explicar cómo se relacionan los usos de la preposición por en expresiones de movimiento y ubicación. Para ello, se basa en la idea de semejanza de familia de Wittgenstein (1953, pp. 31-32). En este sentido, los significados locativos de por se hallan relacionados a la manera de una cadena, pudiendo ocurrir que unos usos no tengan atributos en común con otros de manera directa. En esta cadena se va de un significado más dinámico (de movimiento) hacia uno de ubicación (estático). En el medio, el autor analiza los atributos que tienen en común y que van formando la cadena de sentidos.

Kontturi toma el ejemplo ...y se metió por el primer portal para iniciar la cadena. En este caso, por significa trayectoria unidireccional y momentánea. Luego, un ejemplo como Un tranvía,[...]baja por la calle de Fuencarral, muestra una trayectoria unidireccional y continua. Le sigue el ejemplo Va y viene por entre las mesas del café: en este caso, para el autor, la preposición por significa trayectoria irregular, denominada serpenteante. En el ejemplo andaba por el mundo, la trayectoria es serpenteante, pero además, indica un marco de referencia muy amplio y poco nítido. Finalmente, en el último extremo de la estructura categorial, se encuentra el ejemplo Vive lejos, por Atocha, que no presenta ninguna trayectoria. La preposición por aquí cobra un sentido de 'lugar aproximado' con el resultado final de que ocurre un desplazamiento de sentido dinámico a otro estático. De este modo, se conforma la cadena de significados relacionados mediante la estructura de semejanza de familia.

Esta propuesta resulta muy valiosa porque propone una manera de relacionar los significados de por; sin embargo, el autor reconoce que no considera el resto de los usos de por, más abstractos, como los significados temporales, causales y agentivos. Otro problema que presenta el estudio es que el autor no utiliza ejemplos contextualizados para hacer su análisis semántico, sino solamente oraciones aisladas.

\footnotetext{
${ }^{6}$ Delbecque denomina "objeto preposicional" al elemento que le sigue a la preposición, mientras que llama "sujeto preposicional" a aquel que la precede.
} 
En el presente trabajo, a diferencia de Kontturi, se propone una explicación de las relaciones entre todos los significados de por hallados en una misma muestra.

\section{Algunos problemas pendientes}

Advertimos que en los estudios mencionados previamente, no hay consenso acerca del significado de la preposición por. Algunas gramáticas ofrecen listas de significados, sin ofrecer una sistematización de los usos (De Bruyne, 1999; Real Academia Española, 1973). En contraposición, Fernández Lagunilla y Anula Rebollo (1995) reducen sus usos a un solo valor, el causal. En los trabajos monográficos, algunos autores tampoco proponen una sistematización de los diferentes significados de por; mientras que los estudios afines a la perspectiva del Enfoque Cognitivo Prototípico constituyen buenos antecedentes sobre los que basar la investigación, aunque dejan algunas cuestiones sin resolver. Por una parte, Delbecque (1996) presenta un significado básico de por que resulta demasiado abstracto para poder predecir el resto de los usos. Por otra parte, Kontturi propone relacionar los significados espaciales de por (justamente, los significados más concretos, en oposición a Delbecque), dejando de lado el resto de los significados. El mismo autor admite que su propuesta está incompleta e invita a seguir investigando.

Retomando estos dos últimos planteos, en el presente trabajo se propone una descripción del ítem polisémico de la preposición por, basada en la teoría de categorización radial de Lakoff (1987). Asimismo, se sostiene que el significado básico es el locativo, del cual derivan todos los demás.

\section{Metodología y corpus}

Los principios teóricos expuestos en $§ 1$ y la intención de realizar una descripción que dé cuenta del uso de las formas en sus verdaderos contextos de aparición y diferenciando qué contexto(s) favorece(n) más el uso de cada forma y cuál(es) menos, implican necesariamente una metodología cualitativa y cuantitativa, sobre corpus auténtico en una determinada población y en un momento determinado.

Para demostrar la hipótesis principal de que la preposición por constituye un ítem polisémico con estructura de categoría radial cuyo significado central es el de locativo (espacio de extensión imprecisa), se realizará un análisis cualitativo y cuantitativo sobre un cuerpo de datos auténtico. El análisis cualitativo consiste en comparar contrastivamente la forma consigo misma según distintos atributos de sus contextos de uso para extraer las tendencias y articularlas en descripciones autoconsistentes. Esto es, sobre cada ocurrencia de la preposición por en el corpus, se analizan los atributos semánticos que presenta según el contexto de uso; es decir, teniendo en cuenta los elementos que la rodean y la situación comunicativa. En el apartado de análisis del corpus (§6), se presentará en detalle cada significado hallado y se ilustrará cada uno de ellos con ejemplos seleccionados. El análisis cuantitativo, por su parte, consiste en cuantificar la totalidad de las ocurrencias de por según los significados encontrados y según los atributos semánticos más salientes (en este caso, el de imprecisión o precisión, atendiendo al significado básico de espacio de extensión imprecisa).

Los ejemplos analizados se extrajeron del cuerpo de datos oral PRESEEABuenos Aires (Proyecto para el Estudio Sociolingüístico del Español de España y 
de América), que recoge usos de los años 2010-20117. El PRESEEA es un proyecto para la creación de un corpus de lengua española hablada representativo del mundo hispánico en su variedad geográfica y social. La finalidad del PRESEEA es la creación de un corpus sociolingüístico del español de los núcleos urbanos de España y de América Latina.

Dadas las dimensiones demográficas de Buenos Aires y siguiendo las normativas del PRESEEA, se realizaron 90 encuestas. La conversación semidirigida tuvo en cuenta los siguientes módulos temáticos, cuyo orden el entrevistador podía alterar y volver más flexible, según el decurso de la conversación: saludos, el tiempo, el lugar donde vive, familia y amistades, el trabajo, las costumbres, tiempo de ocio, viajes, anécdotas importantes en su vida, situaciones límites o de peligro, la muerte y los duelos, deseo de mejora económica, final de la entrevista. Se evitaron las situaciones demasiado formulaicas. La conversación con cada informante tuvo una duración promedio de 45 minutos, durante los cuales el entrevistador debió interrumpir lo menos posible al entrevistado.

Del total de las entrevistas del PRESEEA-Buenos Aires, se seleccionaron 12 entrevistas, que pertenecen al habla culta de la ciudad, debido a que el resto todavía se encuentra en proceso de desgrabación. Se elige este corpus en particular, no sólo por ser un corpus de recolección propia, sino también porque constituye el corpus más actual del habla de Buenos Aires. De este modo, podremos saber específicamente cómo se distribuyen los significados de por en una población específica, tal como impone la metodología del ECP. El ítem polisémico que constituye por presenta los significados hallados en este corpus específico, en la variedad del español rioplatense. Al ser un corpus oral, se obtiene la espontaneidad necesaria que brinda el uso de la lengua. Queda por completar el estudio con un corpus escrito actual que contemple usos de por que excedan el uso agentivo, ya estudiado en diferentes corpora escritos de Buenos Aires en trabajos previos.

En el corpus PRESEEA-Buenos Aires, se encontraron 612 ocurrencias de por. De ese total de ocurrencias, hay 321 ejemplos que no se tendrán en cuenta para este estudio. Se trata de diferentes significados de por que aparecen en estructuras fijadas (véase la Tabla 1): en primer lugar, el uso de marcadores discursivos que incluyen la preposición por en su constitución (hay 268 ejemplos $/ 83,49 \%$ ), ${ }^{8}$ los usos de por en conectores (31 ejemplos/9,66\%), ${ }^{9}$ en frases hechas $(19 \text { ejemplos } / 5,92 \%)^{10}$ $y$ en frases verbales (con sentido de inminencia) (3 ejemplos $/ 0,93 \%)^{11}$.

\footnotetext{
${ }^{7}$ El corpus PRESEEA-Buenos Aires es resultado del Proyecto de Investigación Plurianual del Consejo Nacional de Investigaciones Científicas y Técnicas (PIP/CONICET) $\mathrm{N}^{\circ} 11220090100089$, dirigido por la Dra. Norma Carricaburo y codirigido por la Dra. Claudia Borzi, que aportó fondos para la recolección y transcripción de los datos. En el período 2010-2012, participé de ese proyecto, y realicé varias de las entrevistas que conforman el corpus.

Para más información, véase: http://www.linguas.net.

${ }^{8}$ Los marcadores discursivos encontrados en el corpus son los siguientes: por lo menos, por ejemplo, por lo general, por un lado, por otro lado, por asi decirlo, por lo pronto, por suerte, por supuesto, por el otro lado, y por ahí. Esta última expresión, que aparece en 108 ocurrencias, fue analizada en profundidad en un estudio previo de reciente aparición (Funes, 2019). En dicho trabajo se postula la hipótesis de que la expresión por ahí constituye un marcador discursivo.

${ }^{9}$ Se encontraron los siguientes conectores en el corpus: por eso, por lo tanto, por lo cual y por más que.

${ }^{10}$ Las frases hechas halladas corresponden a las expresiones hoy por hoy, cada dos por tres y por las dudas.

${ }^{11}$ Ejemplos de frase verbal con sentido de inminencia: estábamos por cerrar y estoy por cumplir.
} 
Tabla 1. Significados de la preposición por en estructuras fijadas en el PRESEEABuenos Aires.

\begin{tabular}{|l|l|l|}
\hline Significado & Cantidad & Porcentaje \\
\hline Marcador discursivo & 268 & 83,49 \\
\hline Conector & 31 & 9,66 \\
\hline Frase hecha & 19 & 5,92 \\
\hline Frase verbal (inminencia) & 3 & 0,93 \\
\hline Total & 321 & 100 \\
\hline
\end{tabular}

Estos usos no serán tenidos en cuenta porque aquí la preposición por no puede separarse de los elementos que la rodean. Esto es, forman una unidad semántico-pragmática indivisible, no susceptible de ser analizada internamente. Para entender por qué el hablante selecciona por en estas estructuras, es necesario investigar cada una por separado y de manera específica.

En el apartado §6.2., se presenta el análisis de una selección de ejemplos que ilustran los distintos significados de por que fueron hallados en el corpus. Se destaca en negrita la preposición por bajo análisis. En la presentación de los ejemplos, en la cita, la "E." corresponde a "Entrevista", y dentro de cada caso, se distingue con "I" al Informante y con "E" al Entrevistador.

El orden de presentación de los distintos significados responde a la manera en que se conceptualizan para conformar el ítem polisémico, esto es, desde el significado más básico y concreto hacia los más abstractos. Se parte del significado de [+Locativo], pasando por el [+Temporal] (mediante metáfora espacial), que da lugar al de [+Causa] (la causa sucede antes que la consecuencia). Del significado causal deriva el agentivo (el agente es la causa de la afectación sobre el paciente), y el significado modal, relacionado con el de causa (metáfora del conducto) por ser el medio por el que se expresa la causa de un hecho. Por último, se encuentra el significado 'en favor de', que se asocia con el significado causal y agentivo (el nombre que acompaña la preposición es la causa o el agente del comportamiento de quien habla). Este último significado es, además, el que presenta menos casos en el corpus.

\section{Resultados}

\subsection{Análisis cualitativo y cuantitativo del corpus}

En cuanto al análisis cuantitativo de las construcciones con por en el PRESEEA, se distribuyen de la siguiente manera: sobre un total de 291 ejemplos, 124 (42,61\%) pertenecen al significado causal. En cantidad, le sigue el significado locativo (entendiendo por 'locativo' cualquier tipo de significación espacial, ya sea de trayectoria o ubicación) con 97 ejemplos (33,33\%). Luego, hay 23 casos de significado modal (7,9\%); 19 casos de significado temporal (6,53\%); y los valores semánticos con menor frecuencia de uso: el significado 'en favor de', con 15 ocurrencias $(5,16 \%)$ y el significado agentivo, con 13 ejemplos (4,47\%). El significado agentivo es el que menor frecuencia presenta, a pesar de ser el primer uso que mencionan varias de las gramáticas. De todos modos, como veremos en el 
análisis de los ejemplos, esto puede deberse a la naturaleza oral del corpus. En la oralidad, hay un uso muy marginal de la voz pasiva ${ }^{12}$.

A continuación, en la Tabla 2 se presentan los valores y los porcentajes de los significados de por hallados en el corpus.

Tabla 2. Significados de la preposición por en el corpus PRESEEA-Buenos Aires.

\begin{tabular}{|l|l|l|}
\hline Significado & Cantidad & Porcentaje \\
\hline Causal & 124 & 42,61 \\
\hline Locativo & 97 & 33,33 \\
\hline Modal & 23 & 7,9 \\
\hline Temporal & 19 & 6,53 \\
\hline En favor de & 15 & 5,16 \\
\hline Agente & 13 & 4,47 \\
\hline Total & 291 & 100 \\
\hline
\end{tabular}

Cabe recordar aquí que el significado prototípico (locativo) no es equivalente al significado más frecuente. El prototipo no se relaciona con la frecuencia, sino con la acumulación de atributos. Lo que indica esta cuantificación es que, en español actual, hay una tendencia a usar la preposición por para indicar causa y locativo, en ese orden. La alta frecuencia de locativo se explica porque es su significado básico concreto. La primacía del significado causal puede explicarse porque es un significado abstracto básico en la cognición (es la primera relación abstracta que entienden los niños, por ejemplo, antes que la condición o la concesión). La cuantificación también nos indica cuáles son los significados de por más y menos usados en discursos auténticos del habla de Buenos Aires. En combinación con el análisis cualitativo, se desglosará cada uno de estos significados en dos atributos semánticos salientes: el de imprecisión o precisión del contexto semántico que rodea a por (esto es, si junto con los elementos que la rodean, denota significados más precisos, más delimitados, o no). La hipótesis principal de este trabajo postula que el significado básico de por es el locativo, más específicamente, el espacial de trayecto extenso e impreciso. Este atributo de imprecisión recorre todos los usos y los cohesiona en un único ítem polisémico. Esta ligazón semántica explica la relación entre la frecuencia de aparición y los contextos de uso de por.

El atributo de [+imprecisión], entonces, es el que prevalece en todos los contextos de uso, y el que sostiene la categoría radial de por. Por lo tanto, la frecuencia de aparición de ese atributo valida el análisis cualitativo. En la Tabla 3, observamos la cuantificación de dicho atributo en cada valor semántico.

Tabla 3. Atributos [+impreciso] y [+preciso] en los significados de por en el PRESEEABuenos Aires.

\begin{tabular}{|c|c|c|c|}
\hline Significado & Cantidad & Atributos & \\
\hline \multirow[b]{2}{*}{ Causal } & \multirow[b]{2}{*}{124} & Imprecisos & 78 \\
\hline & & Precisos & 46 \\
\hline \multirow[b]{2}{*}{ Locativo } & \multirow[b]{2}{*}{97} & Imprecisos & 75 \\
\hline & & Precisos & 22 \\
\hline \multirow[b]{2}{*}{ Modal } & \multirow[b]{2}{*}{23} & Imprecisos & 14 \\
\hline & & Precisos & 9 \\
\hline Temporal & 19 & Imprecisos & 17 \\
\hline
\end{tabular}

12 El menor uso de construcciones pasivas en la oralidad ha sido cuantificado y demostrado en dos estudios previos (Funes, 2011, 2016). 


\begin{tabular}{|c|c|c|c|}
\hline & & Precisos & 2 \\
\hline \multirow[b]{2}{*}{ En favor de } & \multirow[b]{2}{*}{15} & Imprecisos & 10 \\
\hline & & Precisos & 5 \\
\hline \multirow[b]{2}{*}{ Agente } & \multirow[b]{2}{*}{13} & Imprecisos & 7 \\
\hline & & Precisos & 6 \\
\hline \multirow[b]{2}{*}{ Total } & \multirow[b]{2}{*}{291} & Imprecisos & 201 \\
\hline & & Precisos & 90 \\
\hline
\end{tabular}

En la Tabla 3, constatamos que, en cada significado, prevalece el atributo de imprecisión: 78 casos/124 casos en total en el valor causal; 75/97 en el valor locativo; 14/23 en el valor modal; 17/19 en el valor temporal (casi la totalidad de los ejemplos); 10/15 en el valor 'en favor de'; 7 en los agentivos (aquí se observa una casi paridad en este atributo, en $§ 6.2$. hipotetizamos una razón).

Seguidamente, se ofrece el análisis cualitativo de una selección de ejemplos según el significado encontrado en el corpus.

\subsection{Análisis de ejemplos}

\subsubsection{Ejemplos de por locativo}

1) E.:- ¿Qué preferís, la montaña...?

I.: —La montaña a morir.

E.: - ¿Sí?

I.: - Sí, sí.

E.: - ¿Qué lugares por ejemplo?

I.:- Bueno, yo soy yo de chiquito estuve en Tucumán, que te contaba, yo soy un fanático del norte de mi país (...) la verdad que bueno, estuve por Humahuaca, por Tilcara, por... bueno, por todos esos lugares... las las quebradas y... es una belleza, a mí me gusta mucho la montaña, mucho, mucho, mucho la montaña (PRESEEA, E1: p. 5).

En el ejemplo (1), la preposición por aparece en contexto de significado locativo. Aunque aparecen nombres propios (Humahuaca, Tilcara) y una construcción nominal con cuantificador y demostrativo (todos estos lugares) luego de la preposición, se advierte cierta extensión en el lugar señalado por el entrevistado, y también cierta imprecisión, porque nos dice que estuvo en todos esos lugares como ejemplos del norte argentino, pero sin especificar cuáles son exactamente todos los que visitó. Aparecen asociados a su preferencia por estar en la montaña. La elección de por en lugar de en nos da la idea de trayectoria, de cierto recorrido por el lugar.

2) E.: - ¿Y cuál era tu barrio cuando eras chico?

I.: - Las Cañitas.

E.: - ¿Dónde es eso, en Capital?

I.: - Las Cañitas es eh.. por el Hospital Militar, por donde...

E.: - ¿Donde están los restaurantes ahora?

I.: -Claro, por ahí, ahí vive mi vieja, mi vieja vive en la casa misma, en la misma casa de hace mil años (PRESEEA, E2: p. 5).

En (2) se observa mejor el significado de imprecisión que conlleva el uso de por en contexto locativo. El entrevistado debe ubicar el barrio Las Cañitas dentro de la ciudad de Buenos Aires. Para hacerlo, duda y señala como referencia un hospital: "Las Cañitas es eh.... por el Hospital Militar". A pesar de que el Hospital Militar es un nombre propio y de referencia única (es el único hospital con ese 
nombre dentro de Buenos Aires), al estar acompañada de por, entendemos que se refiere a 'la zona del hospital Militar'. Las Cañitas abarca más allá del hospital, pero este sirve de punto de referencia para ubicar la zona mencionada. Entonces, la preposición por denota la extensión imprecisa del barrio de Las Cañitas, y se refuerza esta imprecisión con la expresión por ahi más adelante en "Claro, por ahí, ahí vive mi vieja".

3) E.: — ¿Al aire libre, a espectáculos, más o menos por dónde va tu perfil? I.: - Y... voy a recitales, muchos recitales, voy a... trato de hacer cosas de aire libre, aunque hago pocas, aunque no hago tantas, eh... la primer (sic) semana de enero vamos a ir al campo de Luciano, Fuseti, eh... por San Pedro a $160 \mathrm{~km}$, pileta, caballos, yo te lo recomiendo, te invito y te recomiendo. (PRESEEA, E2: p. 7).

En (3), para señalar la ubicación del campo de Luciano Fuseti, el entrevistado no logra recordar la ubicación exacta, entonces señala la zona con por: por San Pedro, que no significa 'en San Pedro' sino 'cerca de San Pedro'. Y agrega el modificador a $160 \mathrm{~km}$, es decir, es más allá de San Pedro, en realidad. Una zona extendida e imprecisa.

La mayoría de los ejemplos denotan extensiones espaciales imprecisas, sin embargo hay algunos ejemplos que señalan lugares específicos, como (4):

4) E.:-Eh... ¿es inseguro el barrio o es...?

I.: -Eh... no es el barrio eh... eh... inseguro. Yo creo que este... el país está inseguro, ¿mmm?, eh... que no hay un lugar más o menos seguro que otro; hay ocasiones en las cuales este... eh... uno se vuelve muy inseguro, eh... puede ser tanto en una salida nocturna, como a las tres de la tarde, como a las nueve de la mañana, eh... este... la sociedad y y el estado eh... se ha alejado un poco de lo que es este... el derecho, eh... de las obligaciones, eh... y y esto hace que este... el no respeto por la norma eh... sea un un país inseguro.

E.: - ¿Alguna vez te tocó vivir una situación así?

I.: -Sí...

E.: - ¿A vos o a alguien de tu familia, [I.: Sí, sí...] o cercano?

I.: - A mí, a mí... eh... eh... fue alrededor de las dos y media de la tarde, eh... cuando tuve que detenerme en un semáforo, rodeada de autos, en una calle multicarril, eh... en el cual un una moto se para a la par, estalla en el vidrio y la persona que iba atrás de la moto ingresa en el auto por la ventanilla, eh... y se lleva eh... mi cartera y un saco. (PRESEEA, E12: pp. 6-7).

En (4), la ventanilla denota el lugar específico por el que ingresó el ladrón para robarle la cartera y el saco a la entrevistada. Ya no se trata de un lugar extenso sin límites precisos. De todos modos, la preposición por no señala ubicación (es decir, lugar estático), sino que indica la trayectoria que recorrió el brazo del ladrón.

En (5) y (6) veremos ejemplos locativos algo diferentes, puesto que se trata de proyecciones metafóricas ${ }^{13}$ :

5) E.: —Está bien... ¿Y cómo lo conociste?

\footnotetext{
${ }^{13}$ Se entiende por metáfora/proyección metafórica lo postulado por Lakoff y Johnson (Lakoff y Johnson, 1980, 1999). Para estos autores, ninguna metáfora puede entenderse o siquiera representarse adecuadamente de modo independiente de su base experiencial. Las metáforas no son un fenómeno meramente lingüístico, como se consideraba en las teorías clásicas, sino que conciernen a la categorización conceptual de nuestra experiencia vital, conciernen al conocimiento, ya que la función primaria de las metáforas es cognitiva y ya que ocupan un lugar central en nuestro sistema ordinario de pensamiento y lenguaje. Las metáforas nos permiten entender sistemáticamente un dominio de nuestra experiencia en términos de otro y se construyen dentro del sistema cultural en que se vive. En el ejemplo (5), se entienden las empresas para las que trabajó el hablante a lo largo del tiempo como una serie de espacios que habitó.
} 
I.: - Muy raro... eh... en una fiesta, en una... como en un cumpleaños en un... en una casa muy linda en Buenos Aires, en un edificio antiguo muy lindo que hacía un chico que que vivía en Estados Unidos, que es argentino, había hecho un cumpleaños y yo estaba pasando por una etapa un poco bajón, estaba medio triste porque... la verdad es que no recuerdo por qué, pero creo que había habido algunos problemas de familia, algo algo había pasado, no me acuerdo; y este... y me lo... lo lo vi ahí y unos amigos míos dijeron "Mirá, ese chico es muy para vos", y yo digo "No, déjenme tranquilo, yo quiero estar solo, quiero seguir con mi vida, mi pintura, mi trabajo, qué sé yo, yo no quiero vincularme con nadie, qué sé yo...", y ellos este... hicieron toda una tramoya como para que... conseguí el número de teléfono y que lo llame, lo llamé, fuimos a comer una noche, lo invité a comer afuera.

(PRESEEA, E1: p. 13).

6) E.: - ¿Qué hacías?

I.: - Como cadete empecé a trabajar y desde los diecisiete empecé a trabajar permanente en una empresa, fui pasando por distintas empresas, muchas de ellas, hasta que me recibí y cuando me recibí, empecé a trabajar solo, pero, en realidad, desde los diecisiete a los cuarenta y cinco que tengo ahora, que estoy por cumplir, no paré nunca. (PRESEEA, E5: p. 5).

Los usos metafóricos parten de una base espacial, y de un verbo que también se asocia a lugares y a movimiento, pasar. En los ejemplos, la etapa bajón y las distintas empresas son conceptualizadas como lugares por los que hay que pasar. Las distintas empresas constituye una construcción nominal más cercana a lo concreto, porque son lugares físicos en algún sentido, mientras que la etapa bajón es una construcción más abstracta y tiene que ver con una vivencia del entrevistado.

En (5), el hablante cuenta que tuvo que pasar por "una etapa bajón", que, deducimos, tiene una cierta extensión en el tiempo. De este modo, por contribuye a una interpretación de lugar extendido de cierta imprecisión (no se sabe exactamente cuánto duró esa etapa), que hay que atravesar en el tiempo. Entendemos el paso del tiempo de manera metafórica, como si fuera un lugar físico. Mientras que, en (6), las distintas empresas van marcando puntos en esa línea temporal. El entrevistado trabajó en cada empresa durante cierto tiempo, y eso es conceptualizado como puntos en el espacio que se van atravesando.

En síntesis, los usos locativos de por se anclan en el significado más básico espacial, pero en su mayoría, indican lugares de gran extensión imprecisa, tanto en los usos concretos como en los usos metafóricos. Se señala un trayecto, pero más bien poco delimitado. Esta imprecisión puede reforzarse mediante el uso de artículos indefinidos (por una etapa), nombres en plural sin determinante (por distintas empresas), y adverbios locativos como ahi. En los casos en los que acompaña un nombre propio (por San Pedro) o un artículo definido (por el hospital Militar), entendemos el significado de imprecisión a partir del contexto situacional: no se trata de la locación específica de la ciudad de San Pedro o del hospital, sino de la zona de cercanía de dichos lugares. En contraste, se encuentran los usos locativos específicos, en los que la preposición por se acompaña de artículos definidos (por la ventanilla).

En los usos metafóricos, se replica la idea de trayecto, de camino que hay que transitar. Caminos que tienen una cierta extensión y de los que tampoco sabemos los límites con precisión. 


\subsubsection{Ejemplos de por temporal}

7) E.:- ¿Me contás uno de esos días, desde que empieza, qué hacés, a qué hora te levantás?

I.: - Me levanto... me levanto muy temprano, para lo que debería este .. ponele siete y media u ocho, cuando tengo voluntad medito, eh.. y después, bueno, por lo general las clases yo las tengo los días, las tengo por las noches o por las tardes. (PRESEEA, E4: p. 3).

En (7), se observa que las construcciones por las noches y por las tardes denotan el tiempo en el que transcurren las clases que imparte el entrevistado. Ese tiempo no tiene un límite preciso y se entiende que transcurre en una cierta extensión temporal (varias horas a la noche y a la tarde, pero sin precisar exactamente cuánto tiempo duran).

8) E.: - ¿Y por dónde creés que pasaría la solución?

I.: - No. La solución pasa, por lo menos lo que yo tengo claro, es que pasa por generar políticas a largo plazo, que sean independientes de los gobiernos de turno. Es imposible construir una red de subtes de... del triple de la magnitud que tiene hoy si uno supone que solamente uno estableces políticas por cuatro años, esa es la duración del intendente o de un jefe de gobierno. Entonces, si uno establece políticas que duran veinte o veinticinco años, bueno, cualquiera sea el jefe de gobierno, ya acordó previamente que esto es prioritario. Es lo que pasa con la salud, con la educación. (PRESEEA, E6: p. 4).

En (8), la expresión con por refiere a un período de tiempo más delimitado (cuatro años). Sin embargo, no sabemos exactamente ni el inicio ni el final de esos cuatro años (no corresponden al año calendario).

9) E.: - ¿Y en la infancia eran iguales las celebraciones?

I.: - Eran bastante parecidas. Eran bastante parecidas. Tal vez había más... eh... Eran bastante parecidas. Algunas diferencias porque había otros actores, estaban en el caso alguna vez en la casa... de la hermana de mi padre, por ahí en la casa de mi abuela paterna, otra cosa era la casa de mi abuela materna, con mi tía que falleció, eh... era alguna cosa, nosotros éramos chicos. Alguna connotación distinta. Pero, eso, de alguna manera se intenta mantener, qué sé yo, mi madre ha intentado por mucho tiempo mantener esta tradición, digamos, que era mantener la familia unida, con todas las dificultades que eso implica. (PRESEEA, E6: p. 5).

En (9) se aprecia de manera más clara la imprecisión de la duración temporal. A esto contribuye la construcción nominal con el cuantificador mucho (mucho tiempo). No sabemos con precisión por cuánto tiempo se mantuvo la tradición familiar, pero sí sabemos que es un tiempo muy extendido (en consonancia con el concepto mismo de 'tradición').

10) E.: - ¿Y tenés hobbies, por ejemplo?

I.: - Eh, sí, me agarra por rachas. O sea, tuve una época que, todavía lo mantengo, no me animo mucho, pero aprender a andar en rollers, que lo logré, porque bueno, era algo pendiente que lo tenía de chica. (PRESEEA, E8: p. 3).

Al igual que en (9), en el ejemplo (10) entendemos que se trata de períodos de tiempo indefinidos en su duración. El entrevistado menciona los hobbies que posee y dice que no los mantiene de manera sostenida en el tiempo, sino que los practica de manera alternada, aunque con cierta duración temporal. Para esta interpretación, resulta fundamental el significado de rachas, que denota que se trata 
de períodos breves. La preposición por aporta su significado de extensión temporal imprecisa.

11) E.:- ¿Qué es para vos un amigo?

I.: - Es alguien con quien tenés muchas cosas en común, eh... a pesar de las diferencias, fundamentalmente alguien que... eh... comparte la vida con vos de una manera especial y que... no sé... Me ha pasado me ha pasado por ahí de de no ver algunos amigos por un tiempo -buenos amigos- y después volvernos a encontrar y y en una hora ponernos al día y sentir que que ese vínculo estaba intacto, ¿no? (PRESEEA, E9: p. 8).

El ejemplo (11) presenta de manera explícita la palabra tiempo. El artículo indefinido un contribuye a la interpretación imprecisa de la duración del período. Sabemos que el entrevistado no ve a algunos amigos por un tiempo, pero no sabemos la extensión exacta de ese tiempo. De nuevo, por aporta su significado de extensión imprecisa para llegar a esa interpretación.

En el corpus, la mayoría de los ejemplos denotan un tiempo impreciso. Sólo dos ejemplos son más específicos. Se trata de los siguientes:

12) E: - ¿Cómo es un día normal de tus vacaciones?

I: - Eh... me suelo levantar temprano, este... desayuno y leo el diario; a veces este... eh... no quieren que haga ello, porque eh... la lectura del diario muchas veces eh... complica y conflictúa a la persona por la problemática social que que hay, social y/o política, ¿no?, eh... que tenemos; eh... luego nos vamos a la playa durante todo el día, y finalmente volvemos eh... a la noche, salimos a cenar, a veces a caminar, otras veces nos vamos al al teatro, este año eh... este... Daniel, eh... que es mi hijo, fue por primera vez al teatro en Mar del Plata, anteriormente nunca había querido ir, eh... bueno, eh... y son experiencias que creo que enriquecen. (PRESEEA, E12: p. 9).

13) E.: - Tengo que ir a... a parque Rivadavia, justamente a comprar... eh... a ver si consigo unos libros de lingüística, ¿qué día me conviene ir? no sé si está abierto todos los días, ¿cómo voy? ¿cómo me conviene ir, en qué transporte?

I.: - Bueno, yo sé que está abierto todos los días así que me parece que tendrías que ir... eh... por la mañana, y creo que hasta las cuatro de la tarde vas a encontrar gente seguro, así que andá cualquier día de la semana mismo vas a encontrar gente. (PRESEEA, E10: p. 14).

Por un lado, (12) señala un tiempo específico, el de la primera vez de un viaje a Mar del Plata; por otro lado, (13) señala un período que se extiende en el tiempo, pero con límites precisos: lo que dura una mañana entera, dentro de esas horas, la persona puede ir al parque a comprar.

En resumen, en todos estos ejemplos de por temporal, observamos que el significado de extensión y duración imprecisas proviene de la metáfora espacial. Entendemos el tiempo como si fuera un espacio que se desarrolla a lo largo de una extensión sin límites precisos. Aun cuando sabemos que la duración tuvo un principio y un final (como en el caso de por cuatro años o por rachas), se nos presenta como un tiempo indefinido, de cierta extensión. Esta interpretación se ve reforzada por el contexto de nombres en plural, sin artículo (como rachas), con cuantificador sin artículo (mucho tiempo) o con artículo indefinido (un tiempo).

14) E.: - ¿Cómo reaccionaste en ese momento? ¿Le aconsejaste algo?

I.: -Eh... cuando Maggie, que es mi hermana menor, María, tuvo... le agarró anorexia que pesaba treinta y ocho kilos, que bueno... es muy linda Maggie, y todo, pero ya se había pasado de revoluciones, este... me preocupé, pero en realidad yo soy el hermano mayor de una familia donde mis padres son dos excelentes padres 
pero muy inmaduros, nunca crecieron, y sí soy consciente, por un montón de cosas, que el que se ocupó de la familia, el que se ocupó de mis hermanos fui yo, desde muy chiquito, porque mis papás eran muy muy poco responsables con respecto a lo que era la crianza, este... entonces cuando vino la anorexia de Maggie no... yo sabía que... sí, me preocupé, lo tomé, lo lo padecí, y aporté de mí, pero siempre sabiendo que mis viejos iban a aportar mucho menos, pero no porque no quisieran o porque no lo padecieran, sino por inmaduros, no saben eh... enfrentar ningún tipo de responsabilidad, y aún es así, son muy, muy inmaduros. (PRESEEA, E1: p. 11).

En (14), la preposición por introduce una causa expresada mediante un adjetivo en plural (inmaduros). Deducimos que la inmadurez de los padres es la causa de que no hubiesen podido resolver el problema de salud de la hermana del entrevistado. Más adelante, en la misma entrevista:

15) Mis papás no son de tomar las riendas como se debería frente a eso, se lavan un poquito las manos, pero no por malos, creo que por miedo o por inmadurez, me parece. (PRESEEA, E1: pp. 11-12).

En (15), se refuerza la interpretación con una segunda causa, el miedo, y la repetición de la inmadurez como problema. En ambos ejemplos, la preposición por está acompañada de nombres abstractos sin artículo (miedo, inmadurez). El plural del adjetivo y los nombres sin artículo refuerzan una interpretación de falta de especificidad en la causa del fracaso de los padres para atender los problemas de su hija.

16) E.: ¿ ¿Y un día que tenés que hacer una publicidad, cómo es, más o menos? ¿A qué hora te levantás?

I.: - Y... todos los días son... no, nunca es a la misma hora porque depende de cómo termine el día anterior, depende de que si tengo que trabajar solo o con gente, si tengo que trabajar solo me administro yo, si tengo que trabajar con gente depende de a qué hora quiere empezar a trabajar esa gente, porque cuando yo tengo que trabajar con gente, tengo que trabajar con jefes, digamos, no con gente, con gente que decide...

E.: -Los horarios.

I: -Claro, eh... pero no se madruga, no se madruga, o sea, cuando tengo que trabajar, a menos que haya una corrida infernal por algo que está pasando, el promedio es llegar a las diez, once. (PRESEEA, E2: p. 2).

En (16) también observamos la imprecisión dada por los elementos que acompañan a por: se trata de una construcción nominal formada por un pronombre indefinido (algo) y una subordinada relativa (que está pasando). Ambos elementos constituyen la causa de que haya una corrida infernal y eso lleve al entrevistado a madrugar. La corrida infernal es a su vez la causa del despertar temprano. Además de imprecisa, la causa es hipotética, lo que también contribuye a su falta de especificidad. La corrida se debe a algo que está pasando, que no sabemos qué es ni qué límites presenta.

17) E.: — ¿Y un día que tenés que hacer una publicidad, cómo es, más o menos? ¿A qué hora te levantás?

I.: - $\mathrm{Y}$, en realidad, las festividades religiosas las sigo más por cuestiones sociales que por creencias personales. (PRESEEA, E5: p. 6).

En (17) aparecen también construcciones nominales en plural, sin artículo, que contribuyen al significado de imprecisión. El entrevistado sigue celebrando festividades religiosas por cuestiones sociales, por creencias personales. Es decir, 
por causas no específicas, sino más bien generales. Se diría que no sabe bien por qué continúa con la tradición de los festejos.

18) E.: — ¿O el Día del amigo, por ejemplo, el Día del amigo lo festejás?

I.: - De tratar, sí, bueno, este año no pude, bueno, por cuestiones de tiempo, de coincidir, viste, de ir a tomar un café, sí nos saludamos nos llamamos por teléfono pero no se dio el tiempo como para ese día de juntarse. (PRESEEA, E8: p. 9).

En (18), vuelve a aparecer el nombre cuestiones, también sin artículo y en plural, que ya denota una imprecisión en su significado léxico. Entendemos que el entrevistado no se ve con los amigos por cuestiones de tiempo, es decir, una causa poco específica.

En los ejemplos de significado causal aquí analizados, advertimos que la preposición suele estar acompañada de construcciones nominales sin artículo, cuyo núcleo nominal se encuentra en plural. Esto es, generalmente la causa que se señala en el discurso es inespecífica ${ }^{14}$.

Si bien la mayoría de los ejemplos causales denotan causas imprecisas, hay también casos más específicos, como el que sigue:

19) E.: - Igual es [I.: Mi vida es eso.], igual es como que el diseño ya ya estaba incorporado en tu vida [I.: Bueno...] por tu mamá, ¿no?

I.: -Claro, por mi mamá y por mi papá también [E.: Ah...], porque mi papá también es muy artista en realidad.

En (19), la madre y el padre son las razones concretas por las que el entrevistado eligió el diseño como carrera. Si bien entendemos que se trata de una metonimia: la causa no la constituyen los padres en sí mismos, sino su apoyo e influencia.

Vemos entonces que así como por en usos locativos y temporales, indica una extensión imprecisa, en los usos causales en general también parece indicar causas poco precisas.

\subsubsection{Ejemplos de por agentivo}

20) E.: - ¿Cómo creés que manejamos los argentinos?

I.: - Y, terriblemente mal, creo, eh... mal en el sentido no no de no tener habilidad para manejar, sino de no respetar las leyes de tránsito, de exceder el límite de velocidad, de que cada uno hace lo que le parece y eh... y dicho por gente, por amigos que por ahí viven afuera, o que eh... han pasado una temporada acá realmente... manejar en en... bueno en Buenos Aires, ni hablar... pero en Argentina es un caos. (PRESEEA, E9: p. 10).

En (20), observamos que el agente introducido por la preposición por remite a nombres sin artículo. El primero, un sustantivo con sentido colectivo (gente); el segundo, un nombre en plural (amigos). No se especifica quiénes son los que dicen, los que afirman, que en el exterior (fuera de Argentina) se maneja mejor.

21) E.: —¿Dónde estudiaste?

\footnotetext{
${ }^{14}$ Una hipótesis posible sobre el hecho de que las construcciones con por causales se asocien a causas inespecíficas podría ser que las causas más específicas se señalan de otra manera en la lengua, generalmente con cláusulas encabezadas por el conector porque. Desde ya que habría que demostrar esta hipótesis con un cuerpo de datos cuantificado, pero podría pensarse que los distintos tipos de causa son expresados por medio de diferentes estrategias lingüísticas. Sobre las motivaciones semántico-pragmáticas de las cláusulas causales, véanse sobre todo los trabajos de Borzi $(2008,2012)$.
} 
I.: -En El Salvador.

E.: - En la Universidad del Salvador. Bien, eeh, cuando decidiste estudiar Letras, ¿te fijaste en el tema económico a la hora de decidir qué estudiar o lo dejaste en un segundo plano eso?

I.: -Eh, bueno, fue una circunstancia especial, porque viste que volví de Europa, así que, eem, no elegí la Universidad del Salvador en su momento, y quería hacer periodismo, eh y fui recomendada por un amigo de papá, que era periodista.

(PRESEEA, E11: p. 2).

En (21) también observamos un agente poco definido (un amigo de papá). Se utiliza el artículo indefinido y la predicación de que era periodista, pero no se nos dice el nombre propio.

22) E.:-Mira. Bueno, entonces estudiaste Ciencias de la Comunicación y estudiaste Cine en.. ¿era Cine, así, con ese nombre o..?

I.: - Sí, era, sí, era el título era Dirección de cine. En AQUILEA no estoy muy seguro de que fuera ese el título, pero no era una escuela... digamos, ni siquiera sé si estaba reconocida por algún organismo ni siquiera estatal o educativo, era una escuela más de crítica, hacían prácticas, pero el programa era más bien eh desestructurado, era una muy buena escuela de todas maneras pero dudo mucho que tuviera algún tipo de reconocimiento de ningún organismo. (PRESEEA, E4: p. 2).

En el caso de (22), encontramos otra vez una construcción nominal inespecífica, encabezada por un cuantificador indefinido (algún). Señala que se trata de un organismo aunque no sabemos siquiera si es estatal, educativo o de qué tipo.

23) E.: - ¿Acostumbrás a participar de alguna fiesta popular o social?

I.: - Sí, este... sí, eh... a veces he participado en algunas fiestas eh... eh... populares, por ejemplo eh... de los de los pueblos: el día de la fundación de Chivilcoy, hace poco eh... creo que fue el centenario de la fundación de Suipacha, que también estuve en la fiesta del pueblo, eh... y, este... eh... fiestas eh... ¿cómo era el el otro tipo de fiestas?

E.:-Popular o social.

I.: - Y fiestas sociales también. Eh... ya sea, eh... reuniones o este... organizadas por algún laboratorio, o eh... con diferentes colegas, eh... en ocasiones de asistencias de congresos, este... a veces eh... bueno, eh... los congresos no se efectúan en Capital Federal o en el lugar que uno reside y uno viaja, y después hay este... eh... reuniones de cierre de congreso en los cuales uno también participa de ellos. (PRESEEA, E12: p. 8).

En (23), volvemos a encontrar una construcción nominal introducida por un cuantificador indefinido (algún laboratorio), que denota no saberse con exactitud de qué laboratorio se está hablando.

De los pocos ejemplos que se encuentran en el corpus, 7 corresponden a agentes poco precisos; sin embargo, el resto (6 ejemplos) denota agentes más específicos:

24) E.: — ¿Te gusta preparar alguna, no sé, de esas especialidades? ¿o alguna otra?

I.: - ¿Como por ejemplo?

E.:-Eem, buenas salsas, creo. (...)

E.: - La de hoy fue buena, bueno, ¿cómo la preparaste? (...).

I.: - No, eso fue un robo, porque era algo hecha por mi vieja y yo le agregué la salsa blanca. (PRESEEA, E3: p. 19).

En (24), el agente es específico y humano: mi vieja. El pronombre posesivo refuerza esta interpretación. Por lo tanto, no hay una tendencia clara sobre el tipo de agente, y la poca cantidad de ejemplos en corpus oral no nos permite saber si la 
mayoría será imprecisa. De todos modos, lo que sí tienen en común los ejemplos es que se trata de agentes que provocan media o alta afectación en los pacientes. Esto confirma las hipótesis demostradas en corpus escrito, sobre la preposición por como introductora de agentes en contextos dinámicos. El hecho de que por tenga como significado básico un lugar de gran extensión, imprecisa, y no una ubicación, un lugar estático, nos da la idea del movimiento y dinamismo que la propia por porta de manera intrínseca. En el resto de los ejemplos también hemos visto que la preposición por, al denotar extensiones imprecisas, denota a su vez, cierta trayectoria (no sólo espacial sino también temporal, y como causa que provoca una consecuencia).

\subsubsection{Ejemplos de por modal}

25) E.: — ¿Cómo planificás tus próximas vacaciones?

I.: - Cómo lo planifico, sí, trato de, como hice una semana de playa ahora, me gustaría hacer algo de ciudad. Y calculo Nueva York por ahí.

E.: - ¡Ay, qué lindo! ¿Y cómo hacés la planificación?

I.: - Ah, cómo hago la planificación, sí, nos juntamos con amigos y eem nos dividimos las ciudades o bueno, Nueva York por ahí la vamos a hacer entre todos pero, y hacemos todo nosotros.

E.: - Ah, eso está bueno.

I.: - Por agencia por ahí hacemos nada más que el pasaje. (PRESEEA, E3: p. 22).

En (25), el entrevistado usa la preposición por para dar cuenta del medio que utilizó para comprar un pasaje y organizar un viaje. La construcción nominal que le sigue a por no tiene artículo y porta un significado genérico (agencia), no sabemos exactamente qué agencia se contrató, porque no se nos dice un nombre propio. $\mathrm{Si}$ bien denominamos "modal" al significado, entendemos que más que el modo del verbo en cuestión (hacer), es el medio, el instrumento por el que se realiza la acción. El significado de 'medio' sería un subtipo de modo.

26) E.: - Bien. Sí. ¿Podés hablarme un poquito de tu familia? Me dijiste que tenés... estás en pareja. ¿Cómo conociste a tu pareja?

I.: - Por Internet (risas). (PRESEEA, E5: p. 4).

En (26), el nombre que le sigue a por tampoco tiene artículo, y denota el medio por el que se conocieron el entrevistado y su novia.

27) E.: - Hoy en día hay muchas críticas sobre la educación. ¿Vos cómo te posicionás respecto a esas críticas?

I.: - No, yo no veo que la crítica a la educación, la veo más a la crítica a la sociedad. Yo creo que la sociedad está cambiando fuertemente en muchos aspectos y hace que la... la manera de enseñar sea una manera que hay que modificar (...) Está el tema de la tecnología, que es cómo el docente adapta la tecnología y no cómo se opone a la tecnología. Por ejemplo, el examen por computadora. Uno se niega al examen por computadora porque el alumno se copia por wi-fi. En realidad, la pregunta es cómo hacer un examen donde no importa que el alumno se copie por wi-fi. Ese es el desafío. (PRESEEA, E6: pp. 9-10).

Nuevamente, en (27), encontramos nombres sin artículo, que denotan la manera en que se realiza el examen (a través de la computadora) y la vía por la cual el alumno se conecta a Internet y podría copiarse (a través del wi-fi, medio que posibilita la conexión a Internet). 
Si bien la mayoría de los ejemplos denotan medios imprecisos, también se encuentran algunos ejemplos más específicos:

28) E.: - Por consecuencia / eem // ¿tuvo importancia en su momento la posibilidad /o

/ la consideración de ganar / mucho dinero / ganar poco dinero? / ¿cómo fue/ eso? // I.: -Eh / no // a mí / realmente // en el momento en que yo elegí la carrera / era un momento / bueno / como todos en este país / muy difícil // siempre son momentos difíciles en la Argentina / pero era un momento complicado / y / un momento en que se escuchaba por la tele / que / los / eeh / arquitectos / los médicos / eh / los abogados / manejaban taxis /entonces / yo pensé qué / ¿qué voy a hacer? / ¿voy a elegir una carrera / por / el dinero que

E.:-Sí.

I.: - No hay nada seguro / el la elección de una carrera de las tradicionales / ¿o / voy a elegir una carrera que me de satisfacciones al menos a nivel personal? / E.: - Sí

I.: -Y entonces la opción fue por este lado. (PRESEEA, E7: p. 4).

En (28), la tele denota el medio específico por el que el entrevistado escuchó que los profesionales manejaban taxis.

En resumen, la preposición por en contextos de significado modal, ocurre en su mayoría con nombres sin artículo, ya que remite a significados genéricos que denotan el medio, el instrumento o la vía por la que se realiza una acción. En este sentido, el significado modal se relaciona con el causal, a través de la metáfora del conducto: el modo es la vía por la cual se desarrolla la causa de una acción. Esta vía, a su vez, es una metáfora espacial. Retomando el ejemplo (26), Internet es la vía, el conducto, por el que se conocen dos personas, esto es, constituye la causa del inicio de la relación.

\subsubsection{Ejemplos de por con significado de 'en favor de'}

29) E.:- - Tampoco se puede decir que influyó entonces eh... la posibilidad de ganar más plata...

I.: -Bueno, ahí está el tema. Eh...

E.: -Es decir, el hecho de que podía [I.: Yo soy...] ser una...

I.: - Sí, yo soy tan apasionado de lo que hago que en realidad me... a veces eh... me olvido de poner mi capacidad al servicio de una un bienestar económico que que por ahí quisiera tener, y que lo tengo, no me puedo quejar de nada de lo que tengo pero siempre uno desea más, o quiere vincularse con... no sé, o buscar... o tener qué sé yo, no sé... soñar con una casa cerca del mar, o o tener la posibilidad de de tener un auto mejor si es posible, o... Yo particularmente eh... mi pasión por lo que hago a veces me hace hacer cosas a las que me olvido de ponerles un precio lógico o o que corresponda, y por ahí no tengo una gran ganancia en algunas cosas. (PRESEEA, E1: p. 3).

En (29), la preposición significa 'en favor de', ya que el entrevistado manifiesta sentir pasión en favor de lo que hace. Como vemos, no especifica qué es aquello que hace, el elemento que sigue a la preposición es una cláusula con relativo conformado por artículo neutro (lo que). Se relaciona con un significado causal y agentivo, ya que podría parafrasearse como 'lo que hago me genera pasión'/ 'lo que hago me apasiona'.

30) E.: - ¿Qué le dirías a Mauricio para mejorar la circulación del transporte?

I.: - Por lo pronto, me parece que lo que tienen que controlar eso, o sea, sobre todo la cosa que me pone muy mal, la gente estacionando en doble fila.

E.: - Sí. 
I.: - Horarios de carga y descarga a cualquier hora. Intentó hacer algo y lo frenó Moyano hijo, pero bueno, es decir, el no respeto por el otro me pone muy mal, y eso creo que se necesita sanciones y muy duras. (PRESEEA, E3: p. 13).

En (30), también observamos la indefinición en el cuantificador otro. La frase el no respeto por el otro tiene un sentido genérico, no hay un otro específico a quien respetar.

31) E.: - ¿Y qué pensás cuando te enterás de que otra persona así... ganó la grande, ganó la lotería de navidad, qué pensás, qué...?

I.: - Qué sé yo, me parece un golazo, sé que nunca me va a pasar porque no me gusta jugar, pero me parece bueno, por esa persona. (PRESEEA, E10: p. 3).

En (31), el significado 'en favor de' de la preposición aparece acompañado de una construcción nominal con demostrativo y un núcleo indefinido, en el sentido de que persona no especifica un referente. El significado es hipotético, ya que esa persona no existe realmente, se pregunta por alguien que gana la lotería en un sentido hipotético, en un mundo posible.

32) E.:- ¿A qué le llamás "estudio" puntualmente?

I.: - Eh... sentarme a estudiar con un libro, y un tema un libro de medicina obviamente, y algún tema en el que he visto algún paciente complicado y que tenga que investigar o ver eh... qué otra cosa le puede estar pasando y qué cosas puedo hacer yo por ese paciente, y entonces la revisión de todo un tema médico, ¿no?, a eso. (PRESEEA, E12: p. 2).

De modo análogo a lo que sucede en (31), en el ejemplo (32), la construcción nominal ese paciente también tiene un significado hipotético e indefinido. Es un paciente cualquiera, que no existe en la realidad, ante el cual el entrevistado enuncia que puede hacer cosas por él, es decir, en favor de él.

En general, los ejemplos muestran que el significado 'en favor de' se asocia a nombres indeterminados, poco precisos. Sin embargo, hay casos un poco más específicos:

33) E.: - Y entonces, por ejemplo, ahora que hablábamos un poco del dinero ¿jugó algún papel importante cuando vos elegiste tu profesión o tu carrera?

I.: - No. No. Yo en realidad, este cuando terminé quinto año mirá, siempre el dibujo y la el, la, lo que es plasticidad me gustó. De chica incluso, este, participando de casualidad en un concurso de machas gané el primer premio. O sea, todo lo que es manualidad me gusta, tengo facilidad. O sea, entonces en ese momento donde lo que se elegía era medicina, o abogacía, bueno a mí, realmente me inclinó, a pesar de haber hecho un bachiller biológico, porque bueno, matemática me costaba, este, medicina no se me hubiera ocurrido porque yo veía sangre, veo sangre y me desmayo, entonces eh, bueno, me decidí por la arquitectura y el diseño me gusta en todo, en toda su expresión. O sea, todo lo que sea diseño me gusta. (PRESEEA, E8: pp. 3-4).

Si bien en (33), mediante el artículo definido, podemos precisar más el asunto por el que el entrevistado se inclina a favor, debemos advertir que es un significado genérico, en tanto se refiere a la arquitectura en general como carrera, no a una arquitectura determinada. Con todo, resulta más preciso que los ejemplos anteriores.

En resumen, contamos con pocos ejemplos en el corpus del significado 'en favor de'. Este significado se relaciona con el causal y el agentivo, porque el hablante hace o dice querer hacer cosas por una determinada persona o entidad abstracta. La preposición por co-ocurre con construcciones nominales indefinidas e 
hipotéticas. Esa indefinición se asocia a la extensión aproximada e imprecisa de los usos locativos de por, del cual se derivan en última instancia, todos los usos analizados.

\section{El ítem polisémico por}

\subsection{El modo de categorización radial de Lakoff}

Lakoff (1987, pp. 91-114) retoma la versión extendida de la Teoría de Prototipos de Rosch (1978) y elabora en profundidad el modelo de categorías radiales, a partir del ejemplo ampliamente citado de la categoría madre. Lakoff parte de que un modelo clásico de categorización no puede dar cuenta claramente del concepto de madre, ya que no hay una definición en términos de condiciones necesarias y suficientes (CNS) que pueda abarcar a todos los tipos de madre que existen en el mundo. No comparten todos los atributos la madre biológica, las mujeres donantes de óvulos, las madres sustitutas, las madres adoptivas, las madres solteras o las madrastras. Son todas madres, pero no comparten todos los atributos. Estos problemas suscitados por la categoría madre obligan a repensar la estructura semántica del concepto que la designa. Es por esto que Lakoff aplica, para casos de polisemia, el modelo de la categoría radial. La categoría madre tiene una estructura radial. En esta categoría radial, hay un modelo o miembro central, que es el prototípico, donde está presente la mayor acumulación de atributos comunes a todos los miembros de la categoría. En el caso de la categoría madre, el miembro central es la madre que es mujer, dio a luz a su hijo y además lo crió. El resto de los ejemplos de madre son entendidos como subcategorías, es decir, desviaciones del modelo central.

La estructura radial ayuda a entender los efectos de prototipicidad, dado que una extensión como madre de acogida solo puede ser entendida en relación con el modelo central de madre. Es decir, no puede entenderse por sí misma. Todos los miembros están interrelacionados, de ahí que formen parte de una misma categoría.

El concepto de categoría radial puede explicar que haya elementos no directamente relacionados que formen parte de una misma categoría (Lakoff, 1987, pp. 92-93). Este modelo de categorización tiene en cuenta el sujeto y su experiencia con el mundo. Lakoff concluye de este modo que el sistema conceptual depende de nuestra experiencia física y cultural (1987, p. 112). La teoría de categorización radial resulta útil para estudiar la polisemia. En una categoría, los atributos pueden tener distinto peso. Por ejemplo, el concepto de pájaro puede ser usado para designar un aeroplano (por proyección metafórica). En este sentido, se entiende que las extensiones metafóricas son menos salientes que las otras. Debido a que este modelo resulta pertinente para estudiar la polisemia, se tomará para analizar el ítem polisémico por. La preposición por en español constituye una categoría radial, como se explicará a continuación.

\subsection{La categoría radial de la preposición por}

A partir del análisis cuantitativo del corpus, que nos revela cuáles son los significados de por y cuántos ejemplos hay de cada uno, y considerando el análisis cualitativo de los casos, entendemos que la preposición por constituye un ítem polisémico con estructura de categoría radial. En el Diagrama 1 aparece ilustrado este ítem polisémico. El miembro central de la categoría corresponde al prototipo semántico de por, es decir, el significado que reúne la mayor acumulación de atributos en común. Lo observamos en el círculo remarcado en negrita que se halla 
en el centro del diagrama. Se trata del valor semántico de Locativo, que a su vez, abarca una serie de atributos en relación con el espacio: [+Trayectoria], [+Extensión], [+Imprecisión], como en el ejemplo Estuve por Humahuaca, por Tilcara. Allí observamos que la preposición, junto con los elementos que la rodean, expresan una trayectoria (el recorrido a lo largo de la quebrada de Humahuaca, en el norte argentino) que tiene una cierta extensión, pero que resulta imprecisa porque no se informan los límites del recorrido. Por proyección metafórica, encontramos ejemplos en los que se conceptualiza como espacio un lugar no físico, sino abstracto, como en el ejemplo Fui pasando por distintas empresas. Las empresas en las que trabajó el hablante se conceptualizan como postas en las que se va parando a lo largo de un trayecto.

Luego, del significado espacial se derivan directamente, y también por proyección metafórica, los significados temporales como Me agarra por rachas. En este caso, la temporalidad se compone de los atributos [+Extensión], [+Duración] e [+Imprecisión]. Como se advierte, hay dos atributos en común con el Locativo: se trata de una extensión en el tiempo, es decir, de cierta duración, y a la vez, imprecisa. En el ejemplo, no podemos saber exactamente cuándo comienza y finaliza una racha.

El atributo de [+Imprecisión] también lo encontramos en los significados Modal y 'En favor de'. Esto hace que ambos valores estén directamente relacionados con el prototipo Locativo. En el caso del significado Modal, se agregan los atributos de [+Medio] o [+Causa]. Por ejemplo, en El examen por computadora, la preposición remite al medio por el que se realiza el examen. Si el Modal se asocia a Causa, encontramos ejemplos como La conocí por Internet, en el que Internet es la causa por la que se conoció la pareja. De ahí la línea que une al significado Modal con el de Causa.

Por su parte, el significado 'En favor de', que además resulta ser el de menor frecuencia en el corpus, agrega el atributo de [+Apoyo], como se ve en el ejemplo el no respeto por el otro. Aunque el ejemplo se encuentre negado, entendemos que el respeto hacia el otro es una forma de apoyo, que luego, en el discurso, aparece negada (en el ejemplo 30, el contexto se refiere a la circulación de transportes y el no respeto de parte de los que estacionan hacia los que deben circular).

Del significado temporal se deriva el causal. Como vemos, a pesar de que la causa no derive directamente del locativo, forma parte de la misma categoría porque está relacionado con otro significado que sí se deriva de forma directa del prototipo. El significado Causal tiene los siguientes atributos: [+Origen], [+Motivo], [+Tiempo], [+Imprecisión], como en el ejemplo Las festividades religiosas las sigo más por cuestiones sociales. El sintagma por cuestiones sociales señala el motivo por el que el hablante sigue las festividades religiosas. Este motivo es a su vez origen de la acción de seguir las festividades, y por tanto, incluye un significado temporal, al indicar lo primero que sucede para que ocurra una consecuencia. En el tiempo, en primer lugar, ocurren las cuestiones sociales que motivan al hablante a festejar. El festejo es la consecuencia, ocurre en una segunda instancia.

Al mismo tiempo, se advierte una línea que asocia Locativo y Causal. La relación está dada por el atributo de [+Imprecisión], y esto se vincula con los ejemplos hallados en este corpus en particular, el PRESEEA-Buenos Aires. Allí, encontramos que en los ejemplos causales, la preposición por introducía nombres o construcciones nominales con significado impreciso (genérico, indefinido), como se advierte en el ejemplo citado (cuestiones sociales, en plural y sin artículo). 
Finalmente, del significado Causal se deriva el Agentivo, que tiene los atributos [+Origen], [+Causa], [+/-Humano], [+Afectación]. El agente introducido por la preposición por indica la causa de la acción, es el origen de la acción, puede ser humano o inanimado y provoca una afectación en el paciente. En el ejemplo, hecha por mi vieja, el sintagma mi vieja es el agente [+Humano], el origen de hacer, y que provoca afectación del paciente, que es la salsa (en realidad, es un paciente factitivo, ya que no preexistía, sino que es creada por el agente). Entonces, mi vieja es la causa de que la salsa se hubiese cocinado.

De este modo, los distintos significados de la preposición por se relacionan a través de diferentes atributos y conforman en conjunto la estructura radial de la categoría.

Diagrama 1. Ítem polisémico de la preposición por

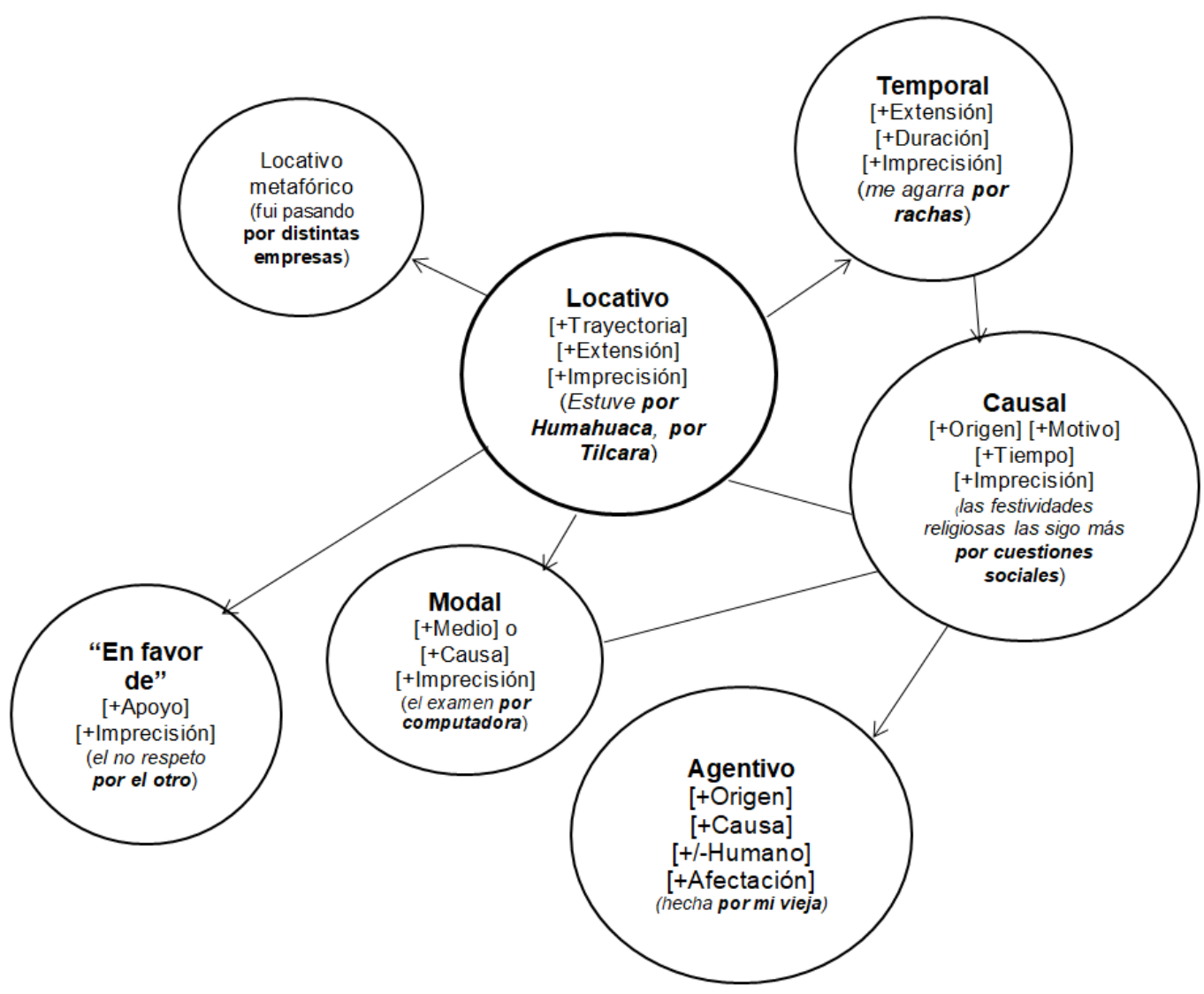

\section{Conclusiones}

A partir del análisis cualitativo y cuantitativo de 12 entrevistas del corpus PRESEEA-Buenos Aires, encontramos que los diversos significados de por se organizan en un ítem polisémico con la estructura de una categoría radial. El significado básico es el locativo, que denota un camino, un trayecto de extensión grande pero también imprecisa. En este corpus en particular, de la variedad rioplatense actual, observamos que el atributo de imprecisión enlaza todos los significados hallados de por, y que los usos más frecuentes son los de locativo (el básico) y el de causa (el abstracto derivado de la metáfora espacial de tiempo). Los usos metafóricos también presentan un camino sin límites precisos. Luego, también 
por proyección metafórica, se entiende la extensión temporal como extensión espacial. Por en sentido temporal denota extensiones de duración imprecisa.

Del significado temporal, surge el significado causal (porque la causa es el origen de un evento, es el primer hecho que ocurre antes que la consecuencia). En los significados causales de las construcciones con preposición por aparecen nombres sin artículo, denotando cierta imprecisión de esas causas.

De la causa, a su vez, se explican los significados agentivos, que son el origen de la acción. En general, el significado agentivo aparece con baja frecuencia en el corpus por ser de naturaleza oral. Cuando aparecen, son agentes indefinidos ( $\sin$ artículo, en número plural o con cuantificador indefinido) y provocan media o alta afectación en el paciente, lo que refuerza el vínculo con el significado de causa, ya que provocan un cambio en el paciente.

En los significados modales, la preposición por denota el medio por el cual se llega a un objetivo, y en ese sentido se relaciona con el significado de causa, por la metáfora del conducto (el medio es el conducto por el que se expresa la causa de un hecho. A su vez, el conducto se desarrolla en un espacio). Acompañan a la preposición nombres sin artículo, es decir, vuelve a aparecer el atributo de imprecisión de la extensión espacial.

Finalmente, hay pocos casos de significado 'en favor de', que se asocia con el significado causal y agentivo (el nombre que acompaña la preposición es la causa o el agente del comportamiento de quien habla). En estos casos, la preposición también aparece en contexto de construcciones nominales indefinidas o hipotéticas, y en este sentido, se asimilan a la imprecisión de la extensión espacial.

\section{Referencias}

1. Alcina Franch, J. y Blecua, J. M (1975). Gramática española. Barcelona: Ariel.

2. Borzi, C. (2008). Tipos de causas introducidas por porque. Espacios Nueva Serie, 3(4), pp. 89-101.

3. Borzi, C. (2012). Gramática y discurso: cláusulas y conectores de la zona causal. Philologus, 18(53), pp. 212-230.

4. De Bruyne, J. (1999). Las preposiciones. En Bosque, I. y Demonte, V. (Eds.), Gramática descriptiva de la lengua española (Vol. 1, pp. 658703). Madrid: Espasa Calpe.

5. Delbecque, N. (1996). Towards a cognitive account of the use of the prepositions por and para in Spanish. En Casad, E. H. (Ed.), Cognitive linguistics in the redwoods: The expansion of a new paradigm in linguistics (pp. 249-318). Berlín-Nueva York: Mouton de Gruyter.

6. Fernández Lagunilla, M. y Anula Rebollo, A. (1995). Sintaxis y cognición. Introducción al conocimiento, el procesamiento y los déficits sintácticos. Madrid: Síntesis.

7. Funes, M. S. (2011). La alternancia de las preposiciones por y de como introductoras del complemento agente. ELUA, 25, pp. 135161. DOI: https://doi.org/10.14198/ELUA2011.25.05

8. Funes, M. S. (2015). Estudio del uso de la preposición de en el español de Buenos Aires. Múnich: Lincom.

9. Funes, M. S. (2016). Caracterización de las construcciones pasivas con complemento agente explícito. Anuario de Letras. Lingüística y Filología, IV(1), pp. 33-68. DOI: 


\section{https://doi.org/10.19130/iifl.adel.4.1.2016.1366}

10. Funes, M. S. (2019). Por ahí es un marcador discursivo: una propuesta cognitiva para el español de Buenos Aires. Oralia, 22(1), pp. 153-166.

11. Geerarerts, D.y Cuyckens, H. (Eds.) (2007). The Oxford Handbook of Cognitive Linguistics. Oxford: Oxford University Press.

12. Guillaume, G. (1953). Psycho-systématique et psycho-sémilogie du language. París: D'Arrey.

13. Kontturi, K. (2010). Sobre los desplazamientos semánticos de la preposición por en expresiones de movimiento y ubicación. En Havu, J. Klippi, C., Hakulinen, S., Jacob, P. y Santiesteban Fernández, J. (Eds.), Actes du XVIIe Congrès des romanistes scandinaves (pp. 673-686). Tampere: Tampere University Press.

14. Lakoff, G. (1987). Women, fire and dangerous things. Chicago: Chicago University Press. DOI: https://doi.org/10.7208/chicago/9780226471013.001.0001

15. Lakoff, G. y Johnson, M. (1980). Metaphors we live by. Chicago: Chicago University Press.

16. Lakoff, G. y Johnson, m. (1999). Philosophy in the flesh. Chicago: Chicago University Press.

17. Langacker, R. (1987). Foundations of Cognitive Grammar. Theoretical Prerequisites (Vol. 1). Stanford: Stanford University Press.

18. Langacker, R. (1987). Foundations of Cognitive Grammar. Descriptive Applications (Vol. 2). Stanford: Stanford University Press.

19. López, M. L. (1972). Problemas y métodos en el análisis de preposiciones. Madrid: Gredos.

20. Morera Pérez, M. (1988). Estructura semántica del sistema preposicional del español moderno y sus campos de usos. Puerto del Rosario: Servicio de Publicaciones del Excmo. Cabildo Insular de Fuerteventura.

21. Pottier, B. (1962). Systématique des éléments de relation: Étude de morphosyntaxe structurale romane. París: Klicksieck.

22. Real Academia Española (1973). Esbozo para una nueva grmática de la lengua española. Madrid: Espasa Calpe.

23. Real Academia Española (2009). Nueva Gramática de la Lengua Española. Madrid: Espasa.

24. Rosch, E. (1978). Principles of categorization. AmsterdamPhiladelphia: John Benjamins.

25. Vidal de Battini, B. (1964). El español de Argentina. Buenos Aires: Consejo Nacional de Educación.

26. Wittgenstein, L. (1953). Investigaciones filosóficas. Barcelona: Crítica. 